\title{
Article \\ Driving Speeds in Urgent and Non-Urgent Ambulance Missions during Normal and Reduced Winter Speed Limit Periods-A Descriptive Study
}

\author{
Jukka Pappinen ${ }^{1,2, *(\mathbb{D})}$ and Hilla Nordquist ${ }^{3}$ \\ 1 FinnHEMS Research and Development Unit, FI-01530 Vantaa, Finland \\ 2 Faculty of Health Sciences, University of Eastern Finland, FI-70211 Kuopio, Finland \\ 3 Department of Health Care and Emergency Care, South-Eastern Finland University of Applied Sciences, \\ Pääskysentie 1, FI-48220 Kotka, Finland; hilla.nordquist@xamk.fi \\ * Correspondence: jukka.pappinen@finnhems.fi
}

Citation: Pappinen, J.; Nordquist, H. Driving Speeds in Urgent and Non-Urgent Ambulance Missions during Normal and Reduced Winter Speed Limit Periods-A Descriptive Study. Nurs. Rep. 2022, 12, 50-58.

https://doi.org/10.3390/

nursrep12010006

Academic Editor: Richard Gray

Received: 4 January 2022

Accepted: 1 February 2022

Published: 3 February 2022

Publisher's Note: MDPI stays neutral with regard to jurisdictional claims in published maps and institutional affiliations.

Copyright: (c) 2022 by the authors. Licensee MDPI, Basel, Switzerland. This article is an open access article distributed under the terms and conditions of the Creative Commons Attribution (CC BY) license (https:// creativecommons.org/licenses/by/ $4.0 /)$.

\begin{abstract}
Objective: Most traffic research on emergency medical services (EMS) focuses on investigating the time saved with emergency response driving. Evidence regarding driving speed during non-urgent ambulance missions is lacking. In contrast, this descriptive study compared registered driving speeds to the road speed limit in urgent A-missions and non-urgent D-missions. Specifically, the study examined driving speeds during normal speed limits, periods of reduced winter speed limits, and speeding during non-urgent D-missions. Methods: Urgent A-missions and non-urgent D-missions were included. Registered ambulance locations and speed data from Pirkanmaa Hospital District, Finland between 1 January 2018 and 31 December 2018 were used. Ambulance locations were linked to OpenStreetMap digital road network data. The registered driving speed distribution was reported as quartiles by the effective road speed limit. Furthermore, the results during the normal speed limit and reduced winter speed limit periods were reported separately. Driving speeds in non-urgent missions were compared with current Finnish traffic violation legislation. Results: As expected, the urgent A-missions exceeded the speed limits during both the normal speed limit and reduced winter speed limit periods. On the smallest streets with speed limits of $30 \mathrm{~km} / \mathrm{h}$, the driving speeds in urgent missions were lower than the speed limit. The driving speeds in non-urgent D-missions were broadly similar throughout the whole year on high-speed roads, and mostly on lower speed limit roads. However, within the $30 \mathrm{~km} / \mathrm{h}$ speed limits, the mean speed in non-urgent missions appeared to increase during the winter. One-fifth of the registered non-urgent D-missions were speeding. Conclusions: Speeding is common in urgent A-missions and non-urgent D-missions throughout the year. Stricter guidelines for EMS are needed to increase driving safety.
\end{abstract}

Keywords: traffic safety; driving safety; emergency medical services; driving speed; urgent ambulance missions; non-urgent ambulance missions

\section{Introduction}

One of the primary traffic safety risk factors is driving speed, and higher speeds increase accident and collision risks [1,2]. A common aim of ambulance missions is to achieve quick access to the target destination [3,4]. However, there is a lack of data concerning the factors affecting the actualized driving speeds in emergency medical services (EMS), and how these speeds compare with speed limits. Emergency response driving permits the use of warning lights, sirens, and exceeding the speed limit. Nevertheless, debates continue regarding whether the clinical benefits of emergency response driving are greater than the increased accident risk for EMS personnel, patients, and other road users [3,5-13]. A recent integrative review [3] highlighted that because of the associations with prehospital time, medical care, and safety aspects, the way an ambulance is driven becomes an important part of prehospital care. 
In Finland, since 2018, a uniform nationwide method has been used to implement an EMS's risk classification system. The risk classification is based on $1 \mathrm{~km} \times 1 \mathrm{~km}$ areas, which are classified based on the Finnish Environment Institute's classifications of core urban, other urban, populated rural, and other areas. Moreover, EMS missions are classified into four urgency classes: $A$ to $D$, where $A$ is the most urgent and D is non-urgent. For the urgent missions (classes $\mathrm{A}$ and $\mathrm{B}$ ), the reach time delays per area are regulated by hospital districts. The reach time is calculated from the time the emergency dispatcher alerts the first EMS unit until the first unit is on site. For example, in the Pirkanmaa Hospital District, 50\% of the A-missions must attain a reach time of $\leq 6 \mathrm{~min}$, and $90 \%$ a reach time of $\leq 10 \mathrm{~min}$ in the core urban areas. For the other urban areas, the target reach times are $\leq 8 \mathrm{~min}$ and $\leq 16 \mathrm{~min}$, and for populated rural areas, $\leq 15 \mathrm{~min}$ and $\leq 30 \mathrm{~min}$, respectively. Finally, reach times for non-urgent D-missions must be $\leq 120 \mathrm{~min}$ in populated areas for $90 \%$ of the missions, and this is uniform nationwide [14]. Notably, ambulances are subject to the same traffic restrictions as other vehicles when undertaking non-urgent missions. Accordingly, it is reasonable to expect that ambulances on D-missions do not need to speed to hit the target reach times.

In Finland, EMS personnel are not professional drivers or even specially trained to drive an ambulance despite driving being a significant part of the role. Driving speed and speeding among general public drivers have been the subject of several studies. A recent meta-analysis concluded that speed is a central risk factor for both accident occurrence and injury severity [15]. One study detailing real-life behavioral data of 3150 volunteers and five million trips in the USA found that mean speeds tend to increase alongside speed limits, but less rapidly in areas with higher speed limits. Furthermore, drivers were found to adapt their speeds based on environmental changes. For instance, drivers reduce their speed limit because of adverse weather conditions, cross-section areas, work zones, and, unsurprisingly, heavy congestion [16]. Moreover, data from a Canadian study with a large real-life speed dataset also noted that on-street parking and the absence of lateral shoulders are associated with restriction compliance [17].

The majority of research examining EMS driving has investigated the time saved with emergency response driving [3,5-13]. Lately, however, ambulance driving safety has received increasing attention $[18,19]$. Recent reviews $[3,20]$ have gathered evidence that time pressure, multitasking, long shifts, and stress have an impact on overall ambulance driving safety. Studies investigating ambulance driving safety [3] typically lack a speeding perspective, especially regarding non-urgent missions. Nonetheless, some evidence exists for urgent missions. A recent Polish study [21] demonstrated that rush hours have no significant impact on ambulance speed during urgent missions, thereby demonstrating that ambulances move at a relatively constant average speed when performing emergency response driving. According to one Finnish study, EMS personnel may show irresponsible and indifferent attitudes when performing emergency response driving [22]. These manifest as excess situational speed, overestimation of driving skills, carefreeness, and carelessness toward other road users [22]. Encouragingly, a recent German study showed that paramedics receiving simulator-based training were positively influenced in terms of the driver's knowledge, attitudes, and real driving behavior, including reducing speeding [23].

Collectively, the background set by these studies strongly recommends avoiding unnecessary speeding in EMS. However, more research is required to develop evidencebased leadership practices and guidelines for better driving safety in EMS [3,24]. Currently, emergency response driving, and non-urgent mission speed estimates are largely educated guesses or outcomes of commercial routing tool estimates. To support better driving safety and planning in EMS, it is vital that accurate driving speed estimates are based on real ambulance driving speeds. In this study, we aimed to examine (1) registered driving speeds compared to the road speed limit in the most urgent A-missions during normal speed limits and reduced winter speed limit periods. (2) Registered driving speeds compared to the road speed limit in non-urgent D-missions during normal speed limit and reduced winter speed limit periods. Finally, we also examined (3) how many of the non-urgent D-missions 
exceeded the speed limits set by Finnish traffic violation legislation. In addition to feeding into traffic safety considerations, the findings of this study can be used to assess driving speed for various spatial and logistics analyses.

\section{Materials and Methods}

This is a descriptive study comprising data on registered ambulance locations and speed data from the Pirkanmaa Hospital District between 1 January 2018 and 31 December 2018. Pirkanmaa was chosen as the study area due to its geographical and demographic representativeness, and easy access to the data. The Pirkanmaa Hospital District authorized the study.

Ambulance TETRA-based radio terminals automatically transmit data packets containing the current speed, direction, and location as specified by a pre-determined schedule. These location packets are sent every few hundred meters, yet the exact schedule is not known. In the Pirkanmaa area, speed, and location data are stored in a database for statistical and management purposes. The data for the study were generated by Pirkanmaa Hospital District IT services using a proprietary database query.

The data do not contain information about the mission's location or nature, the identity of the paramedics, or the unit ID. The time stamps were coarsened to a one-hour accuracy. Only missions with urgency classes A or D, both in response and transport, were included in this study. Urgency class was included with each location data.

Only ambulance units were included in this study. Accordingly, helicopter, and nontransport units (EMS supervisors, emergency physicians, and medical first responders) were excluded. Moreover, the exclusion criteria also included regions with 0 to $5 \mathrm{~km} / \mathrm{h}$ speeds, as very slow or zero speeds indicate stopping or slow maneuvering (such as parking or turning a vehicle around). Furthermore, inaccuracies in satellite navigation may result in a near zero speed being registered, even for a stationary vehicle.

Each location was connected to OpenStreetMap digital road network data [25] if the location coordinates were within $5 \mathrm{~m}$ of the road line. The road type and speed limit were attached to the location. Subsequently, two datasets were created: an urgent dataset for class A-missions (652,759 locations from 50 ambulances) and a non-urgent dataset for class D-missions (141,140 locations from 42 ambulances).

The distribution of registered driving speeds was reported as quartiles by the effective road speed limit. The findings were reported separately for the normal speed limit and the reduced winter speed limit periods (1 January 2018-9 April 2018 and 25 October 2018-31 December 2018, respectively). During the winter, speed limits were reduced on roads from $120 \mathrm{~km} / \mathrm{h}$ to $100 \mathrm{~km} / \mathrm{h}$. Additionally, driving speeds in the non-urgent dataset were compared with current traffic violation legislation in Finland [26]. MapInfo 17.0 was used for processing geographic data, and SPSS 26.0 was used for statistical analysis.

\section{Results}

Tables 1 and 2 list the registered driving speeds for urgent ambulance missions and non-urgent ambulance missions, respectively. 
Table 1. Registered driving speeds by road speed limit in the urgent ambulance A-mission group.

\begin{tabular}{|c|c|c|c|c|c|c|c|}
\hline & $\begin{array}{l}\text { Speed Limit } \\
(\mathrm{km} / \mathrm{h})\end{array}$ & $n$ & $\begin{array}{c}\text { Average Speed } \\
(\mathrm{km} / \mathrm{h})\end{array}$ & $\begin{array}{c}\mathrm{SD} \\
(\mathbf{k m} / \mathbf{h})\end{array}$ & $\begin{array}{c}\text { Lower Quartile } \\
(25 \%)\end{array}$ & $\begin{array}{l}\text { Median } \\
(50 \%)\end{array}$ & $\begin{array}{c}\text { Upper Quartile } \\
(75 \%)\end{array}$ \\
\hline \multirow{8}{*}{$\begin{array}{c}\text { Normal } \\
\text { speed limit }\end{array}$} & 30 & 1667 & 26.9 & 20.7 & 14.0 & 22.0 & 33.7 \\
\hline & 40 & 4451 & 45.4 & 22.5 & 28.0 & 45.5 & 61.3 \\
\hline & 50 & 7173 & 67.6 & 27.1 & 49.0 & 66.0 & 82.6 \\
\hline & 60 & 8139 & 85.8 & 20.6 & 73.8 & 89.0 & 99.5 \\
\hline & 70 & 5645 & 91.8 & 20.6 & 79.5 & 95.9 & 107.2 \\
\hline & 80 & 17,343 & 104.2 & 22.8 & 92.3 & 107.2 & 119.9 \\
\hline & 100 & 29,321 & 120.0 & 17.1 & 111.3 & 119.9 & 129.2 \\
\hline & 120 & 1212 & 136.9 & 16.4 & 129.2 & 139.2 & 150.0 \\
\hline \multirow{7}{*}{$\begin{array}{l}\text { Winter } \\
\text { reduced } \\
\text { speed limit }\end{array}$} & 30 & 1412 & 27.4 & 17.8 & 17.0 & 26.0 & 33.7 \\
\hline & 40 & 4370 & 43.1 & 21.3 & 27.0 & 42.2 & 56.9 \\
\hline & 50 & 6829 & 65.1 & 24.4 & 49.0 & 63.6 & 79.5 \\
\hline & 60 & 688 & 80.9 & 19.7 & 68.5 & 82.6 & 95.9 \\
\hline & 70 & 5081 & 86.9 & 19.4 & 76.6 & 89.0 & 99.5 \\
\hline & 80 & 22,820 & 102.0 & 20.4 & 92.3 & 103.3 & 115.5 \\
\hline & 100 & 18,689 & 114.3 & 17.3 & 103.3 & 115.5 & 124.4 \\
\hline
\end{tabular}

Table 2. Registered driving speeds by road speed limit in non-urgent ambulance D-mission group.

\begin{tabular}{|c|c|c|c|c|c|c|c|}
\hline & $\begin{array}{l}\text { Speed Limit } \\
(\mathrm{km} / \mathrm{h})\end{array}$ & $n$ & $\begin{array}{c}\text { Average Speed } \\
(\mathrm{km} / \mathrm{h})\end{array}$ & $\begin{array}{c}\mathrm{SD} \\
(\mathrm{km} / \mathrm{h})\end{array}$ & $\begin{array}{l}\text { Lower Quartile } \\
\qquad(25 \%)\end{array}$ & $\begin{array}{l}\text { Median } \\
(50 \%)\end{array}$ & $\begin{array}{c}\text { Upper Quartile } \\
(75 \%)\end{array}$ \\
\hline & 30 & 16,097 & 21.6 & 12.5 & 13.0 & 19.0 & 27.0 \\
\hline & 40 & 66,495 & 30.6 & 14.8 & 19.0 & 31.3 & 40.6 \\
\hline & 50 & 60,261 & 46.6 & 17.5 & 36.3 & 47.2 & 56.9 \\
\hline Normal & 60 & 45,181 & 62.0 & 14.9 & 54.8 & 63.6 & 71.1 \\
\hline \multirow[t]{6}{*}{ speed limit } & 70 & 31,674 & 65.2 & 15.0 & 59.0 & 66.0 & 73.8 \\
\hline & 80 & 64,480 & 78.6 & 16.6 & 71.1 & 82.6 & 89.0 \\
\hline & 100 & 55,146 & 95.6 & 14.5 & 89.0 & 95.9 & 103.3 \\
\hline & 120 & 2998 & 114.0 & 14.9 & 107.2 & 115.5 & 124.4 \\
\hline & 30 & 13,304 & 22.5 & 12.6 & 14.0 & 21.0 & 28.0 \\
\hline & 40 & 61,358 & 30.1 & 14.3 & 19.0 & 30.2 & 40.6 \\
\hline Winter & 50 & 52,754 & 45.9 & 16.6 & 36.3 & 47.2 & 54.8 \\
\hline reduced & 60 & 41,553 & 60.7 & 14.5 & 54.8 & 61.3 & 68.5 \\
\hline \multirow[t]{3}{*}{ speed limit } & 70 & 29,124 & 65.3 & 13.3 & 61.3 & 66.0 & 73.8 \\
\hline & 80 & 78,749 & 79.0 & 14.8 & 73.8 & 82.6 & 85.7 \\
\hline & 100 & 33,585 & 93.5 & 14.7 & 85.7 & 95.9 & 103.3 \\
\hline
\end{tabular}

During urgent missions, driving both relatively and absolutely in excess of the speed limits took place on roads with 60 or $80 \mathrm{~km} / \mathrm{h}$ speed limits (Table 1). The speeds were generally lower during the reduced winter speed limit period. Nevertheless, a similar trend was visible during the normal speed limit period. Notably, on streets with a $30 \mathrm{~km} / \mathrm{h}$ speed limit, both the average and median driving speeds were lower than the speed limit.

During non-urgent D-missions, the driving speeds were broadly similar (Table 2). However, on roads with a 60 and $80 \mathrm{~km} / \mathrm{h}$ speed limit, the median speed exceeded the speed limit both during the normal speed limit and the reduced winter speed limit periods. In locations with a $30 \mathrm{~km} / \mathrm{h}$ speed limit, the mean speed appeared to increase during the reduced winter speed limit period compared to the normal speed limit period.

A total of $21.2 \%$ of the registered speeds would have resulted in a penalty (Table 3), with $3.6 \%$ of them exceeding the criminal fine limit ( $>20 \mathrm{~km} / \mathrm{h}$ overspeed). Again, the majority occurred on roads with 60 or $80 \mathrm{~km} / \mathrm{h}$ speed limits (Figure 1). 
Table 3. Distribution of registered driving speeds in non-urgent ambulance D-missions by Finnish traffic violation legislation.

\begin{tabular}{cccc}
\hline Speed Limit $\mathbf{( k m} / \mathbf{h})$ & $\begin{array}{c}\text { Within } \\
\text { Limits } \mathbf{( \% )}\end{array}$ & $\begin{array}{c}\text { \% of Registered Driving Speeds } \\
\text { Max. 20 km/h Overspeed } \\
\text { (Administrative Traffic Violation) }\end{array}$ & $\begin{array}{c}\mathbf{2 0} \text { km/h Overspeed } \\
\text { (Criminal Income-Based Fine) }\end{array}$ \\
\hline 30 & 90.0 & 7.1 & 3.0 \\
40 & 86.9 & 11.3 & 6.8 \\
50 & 79.1 & 14.9 & 5.8 \\
60 & 65.8 & 28.5 & 1.5 \\
70 & 86.7 & 11.8 & 4.2 \\
80 & 73.9 & 21.9 & 1.8 \\
100 & 77.9 & 20.3 & 0.1 \\
\hline 120 & 84.9 & 15.0 & 3.6 \\
\hline
\end{tabular}

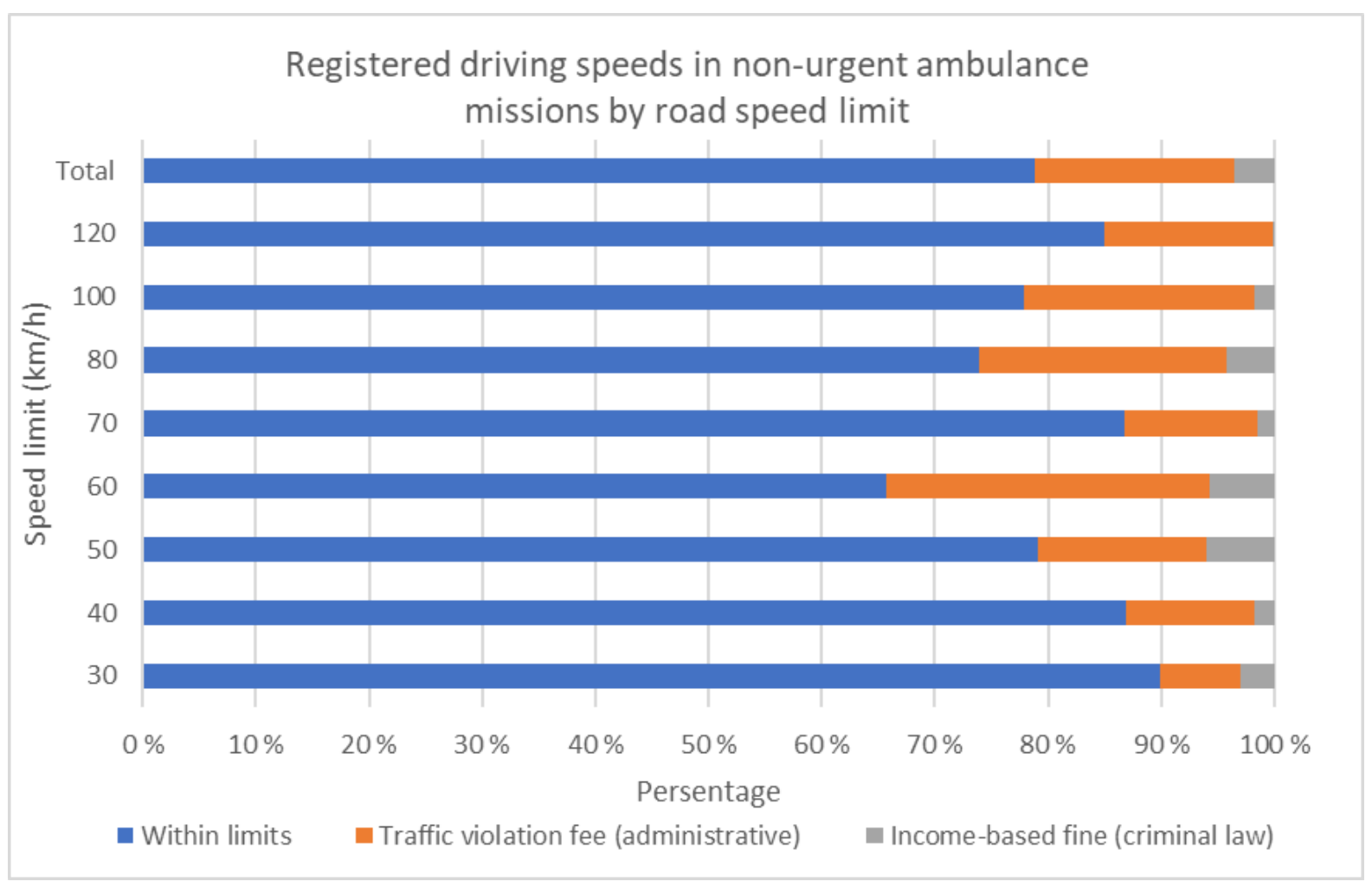

Figure 1. Registered driving speeds in non-urgent ambulance D-missions by road speed limit.

\section{Discussion}

We examined registered driving speeds by road speed limit in urgent A-missions and non-urgent D-missions during the normal speed limit and reduced winter speed limit periods. We also examined speeding during non-urgent D-missions. Our primary findings included: (1) Urgent A-missions showed driving speeds that exceeded the speed limits during both normal speed limits and reduced winter speed limit periods. (2) On the smallest streets with a $30 \mathrm{~km} / \mathrm{h}$ speed limit, the driving speeds in urgent A-missions were lower than the speed limit. (3) In the non-urgent D-missions, the driving speeds were broadly similar throughout the whole year on high-speed limit roads and mostly on lower speed limit roads. (4) In non-urgent D-missions, within the $30 \mathrm{~km} / \mathrm{h}$ speed limit, the mean speed increased during the winter. Finally, (5) one-fifth of the registered non-urgent D-missions were classed as speeding. 
Speeding during urgent EMS missions is common and is expected to a degree, as it is considered a means of reducing response time. The time saved when performing emergency response driving varies from study to study [5-13]. Geographical differences are a possible explanation. For instance, Murray et al. [13] noted that studies conducted in more population-dense areas tended to show a greater amount of time saved with emergency response driving compared to studies conducted in rural areas. These findings are in keeping with expectations, as during an emergency response, ambulance driving typically deviates from traffic rules, such as obeying intersection lights or speed limits. Such an impact may be more pronounced in the city than on roads that already dictate high speed limits [16]. Moreover, the finding that the driving speeds on the smallest streets were lower than the speed limits may be associated with the target address search. It can also be linked to drivers demonstrating extra vigilance with the driving environment, as $30 \mathrm{~km} / \mathrm{h}$ streets tend to go through dense residential areas. It should be noted that this study was conducted in a geographically large hospital district with core urban, other urban, populated rural, and other areas, such as forests with no settlements but many hiking activities. Consequently, the results cannot be easily interpreted based on geographical elements or differences in target reach times of different risk classification areas. Accordingly, this phenomenon should be investigated in greater detail in future studies.

Evidence of driving speed during non-urgent ambulance missions is lacking. Previous studies conducted on the general public have shown that drivers adapt their speed to the environment, such as in cases of adverse weather conditions, drivers were found to reduce their speed [16]. In contrast, a recent study from Poland established that ambulances move at a constant speed regardless of the season [21]. The data collated in this study is limited with respect to examining this association. However, given the current results, this phenomenon was not observed. Thus, it would be interesting to undertake future studies that would investigate whether an association exists between registered ambulance speeds and weather statistics. One such study could examine ambulance speed associations with depth of snow in winter in Finland, which ranges between 10-60 cm and lasts between 100-145 days in the Pirkanmaa area [27]. Currently, this statistic is uncertain. In addition, it may be useful to examine further the increasing speeds during the winter period on $30 \mathrm{~km} / \mathrm{h}$ roads. This association may require more detailed location studies. However, it is worth noting that this speed limit group had the smallest number of overspeeds. Thus, this finding may not be associated with real-life risk-taking.

One notable finding of this study is that speeding in non-urgent missions is common. There was no clear pattern between the number of overspeeds and the speed limits, as the proportions varied between the speed limit categories. Considering that the EMS personnel in this study were performing work duties and that ambulances are under continuous public scrutiny in traffic, a large number of remarkable overspeeds is concerning. As ambulances on non-urgent missions are subject to the same traffic restrictions as other vehicles, and the non-urgent D-missions should not require speeding in terms of target reach times, this finding hints at irresponsible and indifferent attitudes [22] toward obeying speed limits, even when on duty. Previous evidence $[2,3,20,23,24]$ and findings of this current study demonstrate that there is a need for driver training and stricter driving guidelines in EMS.

A study by Bui et al. established that the risk of a crash increased substantially for every kilometer exceeding the speed limit in non-urgent missions [2]. Concerns need to be raised when considering the speeds recorded in the urgent missions and previous evidence that there might be some undesirable attitudes—at least from a safety perspective-associated with emergency response driving. For instance, these attitudes may be born of a greater sense of power, a likelihood of overtaking whenever possible, risk taking, aggression, overconfidence, frustration, and lack of concentration [20,22,28]. In general, transportationrelated injuries constitute a significant proportion of occupational injuries among EMS workers [3,20,24,29-31]. Moreover, EMS workers' indifference toward traffic violation legislation makes a significant contribution to risks [2,32]. Given that ambulance crashes 
occur during emergency response driving and during normal, non-urgent driving [19,33], there is evidently a clear need to improve risk awareness and driving safety in EMS [3,24].

The results of this study can be employed to estimate an ambulance's catchment area within a set time or patient transport time within specific regions around hospitals. Nonetheless, to generate an impact on real-life driving safety and guideline implementation, there is still a need for more evidence on EMS mission speed estimations. To gain added value for real-life development, the collation of driving data should go beyond the constant average speed assumption [34]. Furthermore, driving speeds should be recorded at significantly shorter intervals using three-dimensional acceleration data. Notably, to increase EMS driving safety, there is not only a need for guidelines and supervision, but also immediate feedback. Previous studies have generated promising results, for example, from onboard safety monitoring and feedback systems, which help address potentially detrimental driving behaviors [2,4,24,30,35-37].

\section{Methodological Considerations}

The strength of this study lies in its examination of real-life, whole-year data and of a large dataset of both urgent and non-urgent ambulance missions. Moreover, this study utilized an automatic ambulance tracking system based on a TETRA radio network. The system reported the speed, direction, and location at preset intervals, which were linked to digital road network data. Nevertheless, the limitation of this data is that the registered locations were often relatively inaccurate, and many locations were outside our preset limit (maximum $5 \mathrm{~m}$ distance from the road's central line). These weaknesses were attributed to older TETRA terminals not utilizing modern augmented satellite navigation systems. Thus, this resulted in relatively modest accuracy levels. In addition, the accuracy may have been further reduced by data compression during transmission.

There appears to be a relatively broad variation in speeds within the speed limit. Nonetheless, this study is aimed at observing seasonal variation only, but more explanatory factors are needed to explain this variation. For further analysis, weather and visibility data should also be assessed and linked to the data. In general, the differences between summer and winter and interquartile ranges are relatively large. Accordingly, separate EMS catchment area estimates for normal speed limit periods and reduced winter speed limit periods should be considered.

The Pirkanmaa Hospital District is the second largest hospital district based on population, and eighth by area. The area is versatile, with a large central city (City of Tampere) with a high-density urban area. Moreover, it has a surrounding rural municipality with a modest population density and, especially in the northern parts of the district, relatively large low-or non-populated rural and forest regions. Thus, this area boasts a good representation of the various area types in Finland. However, the findings of this study cannot be interpreted simply by geographical features or the difference in target response times of different risk classification areas.

\section{Conclusions}

Speeding is common in both urgent A-missions and non-urgent D-missions throughout the year. The speed differences between the normal speed limit and the reduced winter speed limit periods were more evident in the urgent A-missions. In contrast, the speeds were broadly similar in non-urgent D-missions, regardless of the seasonal speed limit. More pronounced differences were observed on the smallest roads with a $30 \mathrm{~km} / \mathrm{h}$ speed limit. Overall, the observation of speeding in non-urgent D-missions is a matter of patient, traffic, and work safety. Consequently, there is a need to develop stricter guidelines to increase overall EMS driving safety.

Author Contributions: J.P. was a major contributor to the data conception and interpretation stages. HN provided valuable input towards both the analysis and interpretation of the data. J.P. and H.N. both equally contributed to the writing of the manuscript. All authors have read and agreed to the published version of the manuscript. 
Funding: The study did not receive any specific funding.

Institutional Review Board Statement: Pirkanmaa Hospital District authorized the study (1 October $2019, \S 73 / 2019)$. The data were anonymized. According to the Finnish legislature and good scientific practice defined by the Finnish National Board on Research Integrity TENK, this study did not require Ethics Committee approval.

Informed Consent Statement: Not applicable.

Data Availability Statement: Data are available upon reasonable request from the corresponding author (https://orcid.org/0000-0002-1174-8669). Map data are copyrighted to OpenStreetMap contributors and are available from https:/ / www.openstreetmap.org. The map data contain data from the National Land Survey of Finland's (NLS) Topographic Database and other datasets, under the NLS Open Data License.

Acknowledgments: We thank Harri Taskinen from Pirkanmaa Hospital District/Tampere University Hospital for his support in collating the research data.

Conflicts of Interest: The authors declare no conflict of interest.

\section{References}

1. Elvik, R. Speed and Road Safety: Synthesis of Evidence from Evaluation Studies. Transp. Res. Rec. 2005, 1908, 59-69. [CrossRef]

2. Bui, D.P.; Hu, C.; Jung, A.M.; Pollack Porter, K.M.; Griffin, S.C.; French, D.D.; Crothers, S.; Burgess, J.L. Driving Behaviors Associated with Emergency Service Vehicle Crashes in the U.S. Fire Service. Traffic Inj. Prev. 2018, 19, 849-855. [CrossRef] [PubMed]

3. Becker, J.; Hugelius, K. Driving the Ambulance: An Essential Component of Emergency Medical Services: An Integrative Review. BMC Emerg. Med. 2021, 21, 160. [CrossRef]

4. Aringhieri, R.; Bruni, M.E.; Khodaparasti, S.; van Essen, J.T. Emergency Medical Services and Beyond: Addressing New Challenges through a Wide Literature Review. Comput. Oper. Res. 2017, 78, 349-368. [CrossRef]

5. Ho, J.; Lindquist, M. Time Saved with the Use of Emergency Warning Lights and Siren While Responding to Requests for Emergency Medical Aid in a Rural Environment. Prehosp. Emerg. Care 2001, 5, 159-162. [CrossRef] [PubMed]

6. Marques-Baptista, A.; Ohman-Strickland, P.; Baldino, K.T.; Prasto, M.; Merlin, M.A. Utilization of Warning Lights and Siren Based on Hospital Time-Critical Interventions. Prehosp. Disaster. Med. 2010, 25, 335-339. [CrossRef]

7. Petzäll, K.; Petzäll, J.; Jansson, J.; Nordström, G. Time Saved with High-Speed Driving of Ambulances. Accid. Anal. Prev. 2011, 43, 818-822. [CrossRef]

8. Rehn, M.; Davies, G.; Smith, P.; Lockey, D. Emergency versus Standard Response: Time Efficacy of London's Air Ambulance Rapid Response Vehicle. Emerg. Med. J. 2017, 34, 806-809. [CrossRef]

9. Brown, L.H.; Whitney, C.L.; Hunt, R.C.; Addario, M.; Hogue, T. Do Warning Lights and Sirens Reduce Ambulance Response Times? Prehosp. Emerg. Care 2000, 4, 70-74. [CrossRef]

10. Jarvis, J.L.; Hamilton, V.; Taigman, M.; Brown, L.H. Using Red Lights and Sirens for Emergency Ambulance Response: How often are Potentially Life-Saving Interventions Performed? Prehosp. Emerg. Care 2020, 7, 1-7. [CrossRef]

11. Custalow, C.B.; Gravitz, C.S. Emergency Medical Vehicle Collisions and Potential for Preventive Intervention. Prehosp. Emerg. Care 2004, 8, 175-184. [CrossRef]

12. Becker, L.; Zaloshnja, E.; Levick, N.; Guohua, L.; Miller, T.R. Relative Risk of Injury and Death in Ambulances and other Emergency Vehicles. Accid. Anal. Prev. 2003, 35, 941-948. [CrossRef]

13. Murray, B.; Kue, R. The use of Emergency Lights and Sirens by Ambulances and their Effect on Patient Outcomes and Public Safety: A Comprehensive Review of the Literature. Prehosp. Disaster Med. 2017, 32, 209-216, Erratum in Prehosp. Disaster Med. 2019, 34, 345. [CrossRef] [PubMed]

14. Hospital District of Pirkanmaa. Pirkanmaan Sairaanhoitopiirin Kuntayhtymän Ensihoidon Palvelutasopäätös Vuodelle 2021 (in English: Pirkanmaa Hospital District Emergency Care Service Level Decision for 2021). Available online: https: / / pelastustoimi.fi/documents / 25266713/55623453/Liite_+PSHP+ensihoidon+palvelutasop $\%$ C3\%83\%C2\%A4\%C3\%83\%C2 \%A4t\%C3\%83\%C2\%B6s+2021+(1).pdf/0bd5ffb6-2e7b-fd19-62fb-dcbb173b6027/Liite_+PSHP+ensihoidon+palvelutasop \%C3 $\% 83 \%$ C2\%A4\%C3\%83\%C2\%A4t\%C3\%83\%C2\%B6s+2021+(1).pdf?t=1625729761517 (accessed on 22 January 2022).

15. Elvik, R.; Vadeby, A.; Hels, T.; van Schagen, I. Updated Estimates of the Relationship Between Speed and Road Safety at the Aggregate and Individual Levels. Accid. Anal. Prev. 2019, 123, 114-122. [CrossRef] [PubMed]

16. Hamzeie, R.; Savolainen, P.T.; Gates, T.J. Driver Speed Selection and Crash Risk: Insights from the Naturalistic Driving Study. J. Safety Res. 2017, 63, 187-194. [CrossRef]

17. Gargoum, S.A.; El-Basyouny, K.; Kim, A. Towards Setting Credible Speed Limits: Identifying Factors that Affect Driver Compliance on Urban Roads. Accid. Anal. Prev. 2016, 95, 138-148. [CrossRef] [PubMed]

18. Jakonen, A.; Mänty, M.; Nordquist, H. Safety Checklists for Emergency Response Driving and Patient Transport: Experiences from Emergency Medical Services. Jt. Comm. J. Qual. Patient Saf. 2021, 47, 572-580. [CrossRef] [PubMed] 
19. Norii, T.; Nakao, S.; Miyoshi, T.; Braude, D.; Sklar, D.P.; Crandall, C. Driving Ambulances Safely: Findings of Ten Years of Japanese Ambulance Crash Data. Prehosp. Emerg. Care 2021, 7, 1-12. [CrossRef]

20. Hsiao, H.; Chang, J.; Simeonov, P. Preventing Emergency Vehicle Crashes: Status and Challenges of Human Factors Issues. Hum. Factors 2018, 60, 1048-1072. [CrossRef]

21. Lupa, M.; Chuchro, M.; Sarlej, W.; Ademec, K. Emergency Ambulance Speed Characteristics: A Case Study of Lesser Poland Voivodeship, Southern Poland. Geoinformatica 2021, 25, 775-798. [CrossRef]

22. Koski, A.; Sumanen, H. The Risk Factors Finnish Paramedics Recognize when Performing Emergency Response Driving. Accid. Anal. Prev. 2019, 125, 40-48. [CrossRef] [PubMed]

23. Prohn, M.J.; Herbig, B. Evaluating the Effects of a Simulator-Based Training on Knowledge, Attitudes and Driving Profiles of German Ambulance Drivers. Accid. Anal. Prev. 2020, 138, 105466. [CrossRef] [PubMed]

24. Bui, D.P.; Balland, S.; Giblin, C.; Jung, A.M.; Kramer, S.; Peng, A.; Aquino, M.C.P.; Griffin, S.; French, D.D.; Pollack Porter, K.; et al. Interventions and Controls to Prevent Emergency Service Vehicle Incidents: A Mixed Methods Review. Accid. Anal. Prev. 2018, 115, 189-201. [CrossRef] [PubMed]

25. OpenStreetMap 2020. Available online: http:/ / openstreetmap.org (accessed on 1 February 2021).

26. Act 729/2018. Tieliikennelaki [Road Traffic Act]. Available online: https://www.finlex.fi/fi/laki/ajantasa/2018/20180729 (accessed on 31 January 2021).

27. Finnish Meteorological Institute. Available online: https:/ / en.ilmatieteenlaitos.fi/snow-statistics (accessed on 2 February 2021).

28. Gormley, M.; Walsh, T.; Fuller, R. Risks in the Driving of Emergency Service Vehicles. Ir. J. Psychol. 2008, 29, 7-18. [CrossRef]

29. Maguire, B.J. Transportation-Related Injuries and Fatalities among Emergency Medical Technicians and Paramedics. Prehosp. Disaster Med. 2011, 26, 346-352. [CrossRef]

30. Sanddal, N.D.; Albert, S.; Hansen, J.D.; Kupas, D.F. Contributing Factors and Issues Associated with Rural Ambulance Crashes: Literature Review and Annotated Bibliography. Prehosp. Emerg. Care 2008, 12, 257-267. [CrossRef]

31. Slattery, D.E.; Silver, A. The Hazards of Providing Care in Emergency Vehicles: An Opportunity for Reform. Prehosp. Emerg. Care 2009, 13, 388-397. [CrossRef]

32. Yasmin, S.; Anowar, S.; Tay, R. Effects of Drivers' Actions on Severity of Emergency Vehicle Collisions. Transp. Res. Rec. 2012, 2318, 90-97. [CrossRef]

33. Missikpode, C.; Peek-Asa, C.; Young, T.; Hamann, C. Does Crash Risk Increase when Emergency Vehicles are Driving with Lights and Sirens? Accid. Anal. Prev. 2018, 113, 257-262. [CrossRef]

34. Budge, S.; Ingolfsson, A.; Zerom, D. Empirical analysis of ambulance travel times: The case of Calgary Emergency Medical Services. Manag. Sci. 2010, 56, 716-723. [CrossRef]

35. Myers, L.A.; Russi, C.S.; Will, M.D.; Hankins, D.G. Effect of an Onboard Event Recorder and a Formal Review Process on Ambulance Driving Behaviour. Emerg. Med. J. 2012, 29, 133-135. [CrossRef] [PubMed]

36. Levick, N.R.; Swanson, J. An Optimal Solution for Enhancing Ambulance Safety: Implementing a Driver Performance Feedback and Monitoring Device in Ground Emergency Medical Service Vehicles. Annu. Proc. Assoc. Adv. Automot. Med. 2005, 49, 35-50. [PubMed]

37. Horrey, W.J.; Lesch, M.F.; Dainoff, M.J.; Robertson, M.M.; Noy, Y.I. On-Board Safety Monitoring Systems for Driving: Review, Knowledge Gaps, and Framework. J. Safety Res. 2012, 43, 49-58. [CrossRef] [PubMed] 